\title{
Morphometric variability of the genus Nodularia (Cyanobacteria) in Baltic natural communities
}

\author{
Roberta Congestri*, Enrico Capucci, Patrizia Albertano
}

Department of Biology, University of Rome ‘Tor Vergata', Via della Ricerca Scientifica, 00133 Rome, Italy

\begin{abstract}
Morphometric variability of the filamentous diazotroph Nodularia was determined in natural, mixed-species samples during a summer cyanobacterial bloom in the Central Baltic Sea using epifluorescence microscopy coupled with image analysis. A total of 1350 cyanobacterial filament images were acquired and a number of morphometric parameters measured for individual trichomes present in the samples and used to distinguish Nodularia from Aphanizomenon and Anabaena. The approach allowed automatic estimates of linear dimensions of Nodularia, Aphanizomenon and Anabaena, enabling us to evaluate their biovolume and vertical distribution, and to observe a high degree of morphometric variability in Nodularia filaments. We statistically analyzed this phenotypic diversity using previously collected datasets and adding further measurements. The data obtained were used to assess the variability in Nodularia trichome width and morphology and to establish the possible existence of 3 Nodularia 'morphotypes' by discriminant analysis.
\end{abstract}

KEY WORDS: Nodularia $\cdot$ Morphometry $\cdot$ Image analysis $\cdot$ Discriminant analysis $\cdot$ Baltic Sea

\section{INTRODUCTION}

Blooms of diazotrophic cyanobacteria occur regularly throughout summer in the Baltic Sea. Heterocystous filaments of Nodularia, Aphanizomenon and Anabaena coexist within the summer cyanobacterial assemblage together with picoplanktonic unicells. The latter can contribute as much as $80 \%$ of total cyanobacterial biomass and $50 \%$ of total primary production in this period of the year (Stal et al. 1999, Stal \& Walsby 2000). The filamentous fraction is the most obvious, with buoyant trichomes and colonies floating up to the uppermost water layer to benefit from the higher irradiance. Large areas of surface aggregates, eventually forming scums, become visible to the naked eye (Kahru et al. 1994, Walsby et al. 1995).

Massive cyanobacterial growth is favoured by the onset of calm, stratified conditions induced by the increase in water temperature and nitrogen depletion (low DIN:DIP ratios) along the water column (Niemi 1979, Kononen et al. 1996). Generally, these conditions occur in July/August after the spring bloom, when combined nitrogen sources are depleted (Kononen et al. 1996, Stal et al. 1999), triggering the growth of heterocystous cyanobacterial species able to fix nitrogen from the atmosphere, and outcompeting nondiazotrophic microorganisms.

Recently, image analysis methods based on phycobiliprotein autofluorescence have been developed to calculate the contribution of various heterocystous genera to the total cyanobacterial biomass in natural samples (Congestri et al. 2000). Computer mediated methods are also known to provide precise estimates of the linear dimensions of filamentous cyanobacteria (Walsby \& Avery 1996), and of cell abundance and the morphometric variability of picoplanktonic chroococcaleans (Albertano et al. 1997). These methods could be useful tools in monitoring bloom forming taxa, especially those associated with toxin production. Baltic Nodularia strains have been shown to produce nodularin, a hepatotoxic cyclic pentapeptide which can act as a liver tumor promoter and direct carcinogen (Carmichael et al. 1988, Sivonen et al. 1989). Extensive blooms of Nodularia are globally distributed in the 
brackish environments of the world (Sellner 1997, Bolch et al. 1999, Moisander \& Pearl 2000), arousing public concern over their potential toxicity. In recent years, long-term data showed increasing trends in bloom quantity and intensity in the Baltic Basin (Finni et al. 2001).

In this study we further tested the method based on epifluorescence microscopy combined with image analysis, as described by Congestri et al. (2000). The approach allowed automatic estimates of linear dimensions of all the heterocystous cyanobacterial genera present in the samples collected during summer 1999 in the Central Baltic Sea. Morphometric datasets of our previous work for each cyanobacterial genus are statistically analyzed in the present paper. Here we focus on Nodularia morphometry. This genus shows the largest variability, leading us to hypothesize a distinction between cell diameter classes within the natural assemblage. This hypothesis was statistically analyzed by discriminant analysis based on an extra dataset collected on Nodularia heterocyst morphometry. The presence of at least 2 distinct and more frequent morphotypes was statistically evidenced. This distinction seemed consistent with the traditional taxonomic assessment of Baltic Nodularia that discriminates between different species on the basis of the morphologic traits of the filaments (Komárek et al. 1993), but is in conflict with recent molecular data that indicate the existence of one species only (Barker et al. 2000a). In any case, our approach allowed automated or semi-automated analysis of the cyanobacterial community structure, thus contributing to a morphologic and morphometric characterization of taxa in natural assemblages, avoiding the loss of diacritical morphologic features and genotypic selection occurring in laboratory culture.

\section{MATERIALS AND METHODS}

Samples were collected during 3 (Stns 12-14) $24 \mathrm{~h}$ experiments (6/7, 8/9 and 10/11 July 1998) at a drift station in the South Gotland Sea (Baltic Sea), 56 $18 \mathrm{~N}$, $19^{\circ} 05$ E, on RV 'Alexander von Humboldt' (Baltic Sea Research Institute, Warnemünde, Germany).

A $100 \mu \mathrm{m}-\mathrm{mesh}$ closing plankton net was towed vertically through the $0-7,7-14$ and $14-21 \mathrm{~m}$ depth layers, at 04:00, 12:00, 20:00, 24:00, 04:00 h (local time), over the 3 diel cycles. Aliquots of concentrated seawater samples, each resulting from 10 net tows at different depth intervals, were fixed on board in $2.5 \%$ glutaraldehyde, diluted in filtered seawater, and kept in $15 \mathrm{ml}$ tubes at $4^{\circ} \mathrm{C}$. A total of 45 samples were collected and transferred to the laboratory.
Some preliminary observations were conducted in light and epifluorescence microscopy (Leica M2 green filter set, excitation wavelength $546 \mathrm{~nm}$, cut-off at $580 \mathrm{~nm}$ ) to evaluate the composition of the microphytoplanktonic community and the morphology of the diazotrophic cyanobacterial genera present in the samples.

In order to estimate the morphometry of the heterocystous cyanobacteria, the samples were processed by means of epifluorescence microscopy coupled with a Quantimet automatic system equipped with an image analysis software, as reported in Congestri et al. (2000).

Statistics were applied primarily to the width datasets of Nodularia, Aphanizomenon and Anabaena, obtained by processing a total of 1350 images. Frequency and descriptive procedures of the SPSS package for Windows were used to analyze class frequency distribution and descriptive statistics of the 3 genera, separately. Each individual genus dataset was first considered as a whole and then pooled according to day, time and depth of sampling.

To further analyze Nodularia morphometric variability, 100 out of 1000 images were randomly selected from Nodularia tif files previously stored (Congestri et al. 2000), with the aim of distinguishing between the different morphotypes. Each randomly selected filament was assigned a priori to Type 1, 2 or 3 according to the trichome morphology evident in epifluorescence microscopy. Morphometry of 225 heterocysts present in these trichomes was evaluated after manual circumscribing them (tracing lines with a mouse along the Nodularia filaments) to determine estimates of width, length, area and perimeter of the highlighted heterocysts. At least 2 heterocysts per filament were measured. When no overlapping or crossing of filaments was present, 3 heterocysts were measured. Heterocyst manual circumscription was conducted using greater magnification in order to achieve a more precise automatic measurement with the image analysis software. Based on a priori classification of filament types, a discriminant analysis was then performed (using the 'Classify; discriminant' procedure of the SPSS package) to construct a predictive model of group membership using the heterocyst morphometric data. This procedure generated linear combinations of the predictor variables which provided the best discrimination between the groups. The functions were constructed from a randomly selected sample consisting of $50 \%$ of the dataset from known groups whose group membership was known. Then we applied the functions to the remaining $50 \%$ to cross-validate the consistency between the a priori classification of types $(1,2,3)$ and the one using the functions. 

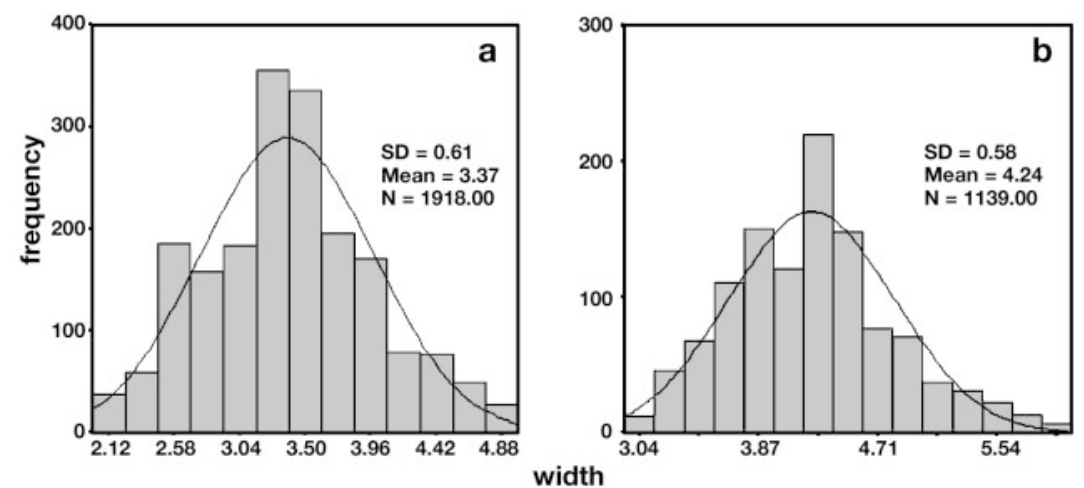

Fig. 1. Frequency distribution of width data, expressed in $\mu \mathrm{m}$, for (a) Anabaena and (b) Aphanizomenon recorded in the samples
Results indicated that Nodularia distributions differed significantly from the normal distribution (Table 1).

This deviation suggested the possibility of distinguishing more than one diameter class in the Nodularia natural assemblage, as also hypothesized during epifluorescence observations. In fact, 3 different morphotypes distinguishable on the basis of their width and other morphologic traits were found to coexist in the recorded images (ca. 1000) containing Nodularia filaments. The 3 'morphotypes' appeared in epifluorescence microscopy as follows: a wider and more common type, labelled as Type 3 (Fig. 4a,b,e), showed individual cells easily visible along the trichome because of the presence of discernible cross-
Nodularia, Aphanizomenon and Anabaena filaments, along with the centric diatoms Chaetoceros, Skeletonema and Thalassiosira spp., and dinoflagellates such as Dinophysis and Phalacroma spp. primarily contributed to the structure and composition of the microphytoplanktonic community sampled at the drift station in the South Gotland Sea in July 1998.

The possible interference signals due to phycoerythrin contained in Dinophysis norvegica and D. acuminata (Carpenter et al. 1995, Hewes et al. 1998) did not hinder cyanobacterial filament resolution under the epifluorescence illumination used during image recording.

Descriptive and frequency analysis conducted on the width datasets of Aphanizomenon and Anabaena, separately, was not able to distinguish different width classes. Class frequency distributions were almost normal (Fig. 1a,b), as shown by histograms pertaining to Aphanizomenon and Anabaena. Nodularia class frequency distributions represented marked deviations from the Gaussian curve. They indicated multimodal patterns both when considering the dataset as a whole or when pooled according to different depths and stations (Fig. 2) and time of sampling (Fig. 3). The Kolmogorov-Smirnov test of normality was then applied to test the hypothesis that the datasets were normally distributed.
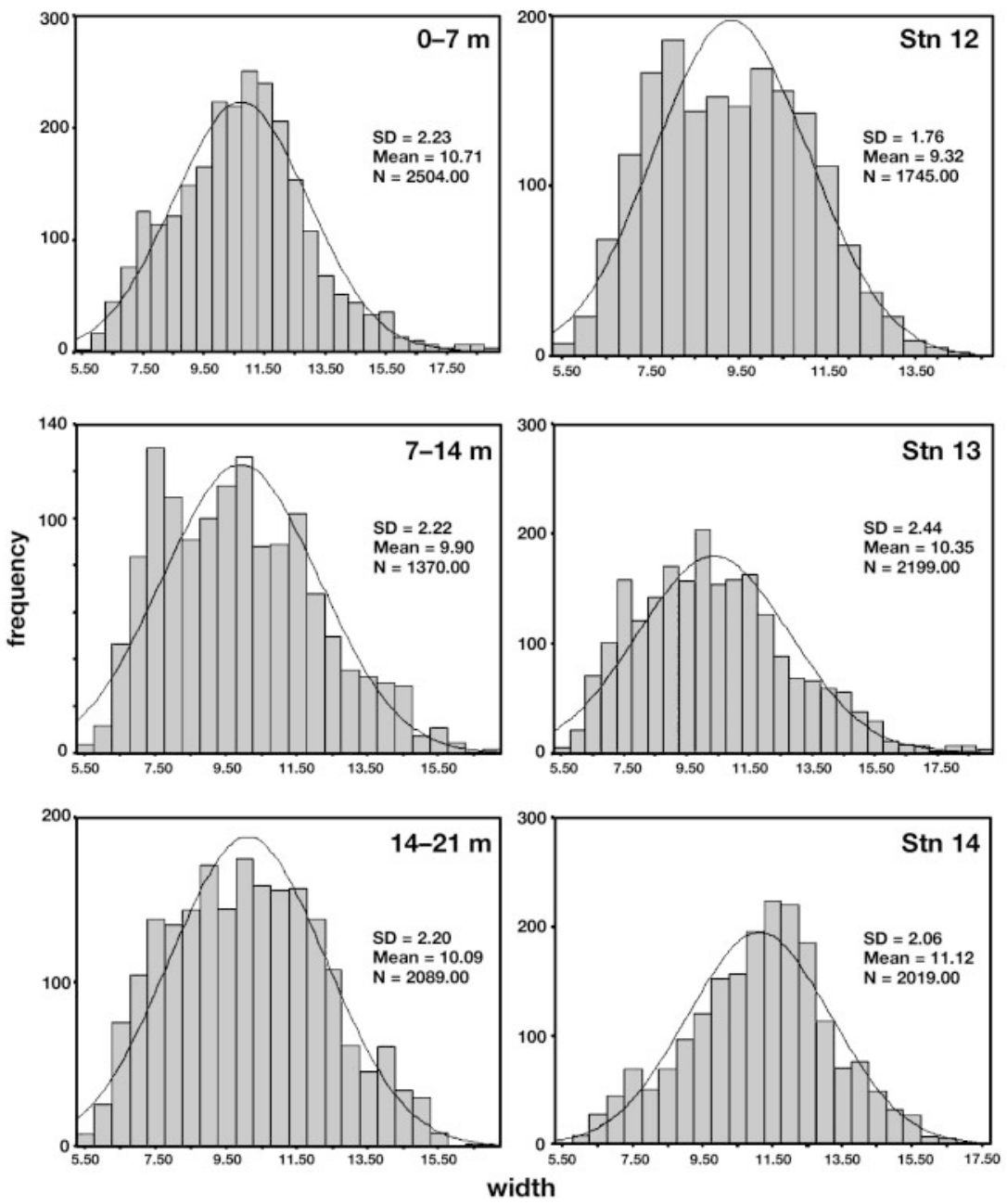

Fig. 2. Nodularia. Frequency distribution of width data, expressed in $\mu \mathrm{m}$, at 3 different depths (0-7, 7-14 and 14-21 m) and stations (Stns 12, 13 and 14) of sampling 


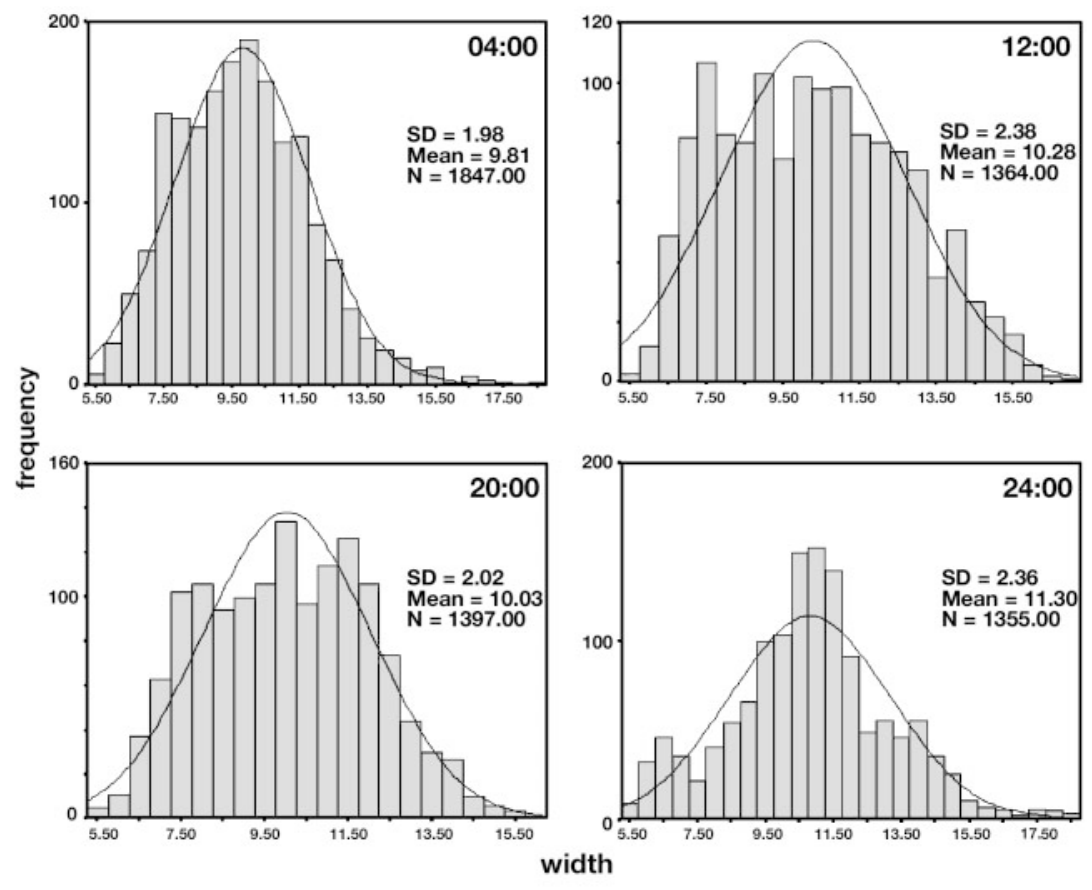

Fig. 3. Nodularia. Frequency distribution of width data, expressed in $\mu \mathrm{m}$, at different times $(04: 00,12: 00,20: 00$ and 24:00 h) of sampling

A discriminant analysis was performed in order to build a predictive model based on microscopical observations and the multimodal patterns revealed by descriptive and frequency procedures. For this purpose, 100 images were randomly selected among those containing Nodularia trichomes and each filament was a priori assigned to a morphologic type. In addition, automatic measurement of the Nodularia filament widths was calculated and stored. Morphometry, namely the length, width, area and perimeter of the heterocysts present along the selected filaments, was evaluated and subsequently used to construct a discriminant function. No akinetes were observed in the filaments, so the heterocyst morphometric traits provided the independent measurements necessary for membership grouping. It is known that Nodularia heterocysts retain their thylakoids for a long time (Šmarda et al. 1988). This retention allowed us to distinguish the heterocysts under epi-

walls. Filaments were usually straight or slightly curved. The length:width ratio of the vegetative cells was barely measurable due to the presence of crosswalls forming in almost every cell. A narrower type, Type 2 (Fig. 4a,c,d), showed short discoid vegetative cells and barely visible cross-walls. Filaments were usually spirally entangled. A third and rather rare type, Type 1 (Fig. 4a,e,f), formed tightly coiled filaments. The heterocysts were oval in shape and visibly wider than vegetative cells, the latter still being the narrowest.

Table 1. Nodularia. Results of the Kolmogorov-Smirnov (K-S) test of normality applied to width data pooled according to different stations, depths and time of sampling. Significance values (p) less than 0.05 indicated that distribution differed significantly from a normal distribution

\begin{tabular}{|lrccc|}
\hline & & K-S statistic & $\mathrm{df}$ & $\mathrm{p}$ \\
\hline \multirow{4}{*}{ Station } & 12 & 0.063 & 1745 & 0.000 \\
& 13 & 0.046 & 2199 & 0.000 \\
Depth (m) & 14 & 0.040 & 2019 & 0.000 \\
& 7 & 0.037 & 2504 & 0.000 \\
& 14 & 0.044 & 2089 & 0.000 \\
Time & 21 & 0.061 & 1370 & 0.000 \\
& $04: 00$ & 0.036 & 1847 & 0.000 \\
& $12: 00$ & 0.063 & 1364 & 0.000 \\
& $20: 00$ & 0.053 & 1397 & 0.000 \\
& $24: 00$ & 0.051 & 1355 & 0.000 \\
\hline
\end{tabular}
fluorescence illumination, and to assume that the measured heterocyst population was at the same developmental stage. A total of 225 heterocysts were measured along the filaments, 53 of which were attributed to Type 3, 34 to Type 2 and 13 to Type 1. This also suggested the relative proportion of the different types in the natural samples. Type 3 was confirmed to be the most common in the samples, Type 2 showed an intermediate frequency and Type 1 was the rarest encountered.

Discriminant analysis allowed coefficients of the linear discriminant functions to be estimated (Table 2). The functions were applied to the subset of cases used to construct the functions themselves. A posteriori classification, based on the predictor variables, matched the original a priori grouping of filament types

Table 2. Nodularia. Coefficients of the Fisher's linear discriminant functions estimated using heterocyst morphometric data of a priori classified filament types $(1,2,3)$

\begin{tabular}{|lrcr|}
\hline & \multicolumn{3}{c|}{ Type } \\
& 1 & 2 & \multicolumn{1}{c|}{3} \\
\hline Area & -1.303 & -1.358 & -1.544 \\
Perimeter & 5.780 & 5.659 & 6.416 \\
Length & -1.216 & $6.670 \mathrm{E}-02$ & 0.673 \\
Width & 11.736 & 12.006 & 13.378 \\
(Constant) & -63.408 & -70.149 & -95.250 \\
\hline
\end{tabular}



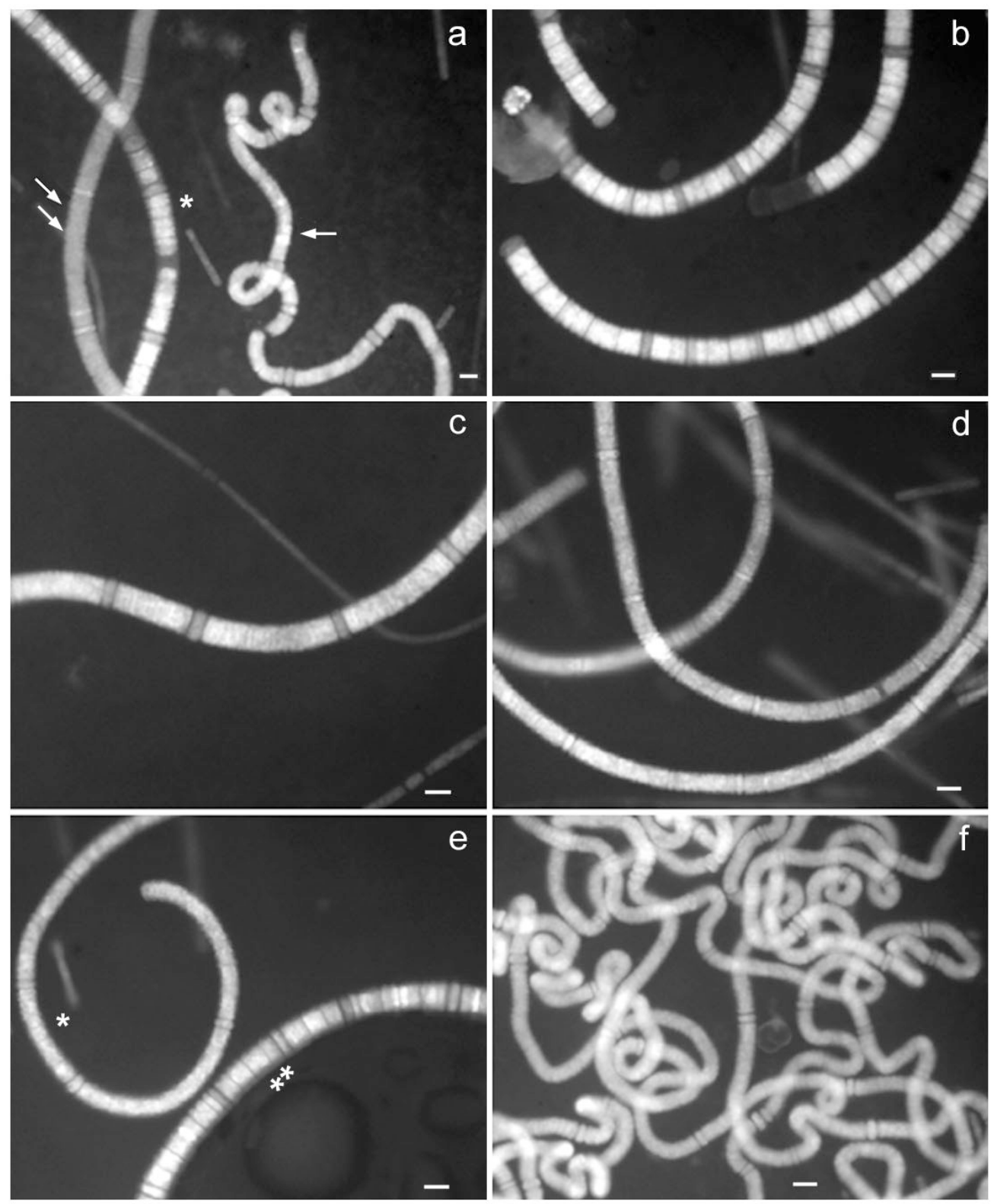

Fig. 4. Nodularia. Epifluorescence recorded images of the 3 morphotypes observed in the samples. Type 1 filaments (a: arrow; e: asterisk; and f) of 7, 7.7 and $8 \mu \mathrm{m}$ widths, respectively. Type 2 filaments (a: double arrow; $\mathrm{C}_{\text {; }}$ and d) of $10.7,10.9 \mathrm{and} 8.9 \mu \mathrm{m}$ widths, respectively. Type 3 filaments (a: asterisk; b; and e: double asterisk) of 12.5, 11.2 and $11.7 \mu \mathrm{m}$ widths, respectively.

Scale bars $=10 \mu \mathrm{m}$

in $84 \%$ of the cases (Table 3 ). When the functions were applied to the $50 \%$ not selected to construct the functions, in order to cross-validate the a posteriori classification, the percentage was 80. In Table 3 we also report the classification results for each filament type, both for selected and unselected subsets of data. The functions correctly discriminated Type 3 in $91 \%$ of the cases and Type 2 in $87 \%$, but appeared unable to discriminate filaments belonging to Type 1 because of their attribution to Type 2 in $80 \%$ of the cases. The scatterplot of combined groups (Fig. 5) is constructed on the basis of canonical discriminant functions, whose coefficients are reported in Table 4. Evidence here shows that Function 1 (mostly correlated with length, perimeter and area, Table 5) clearly separated Type 3 from Type 2 and 1. Conversely, Type 1 and 2 filaments were not clearly distinguished, although Type 1 was localized towards the lowest values of the Function 1 axis. Function 2, mostly correlated to width (Table 5), did not provide any evidence of discrimination between the groups. 
Table 3. Classification results obtained applying the discriminant functions to the subsets of cases selected and not selected for their construction. In all, $84.4 \%$ of selected original grouped cases were correctly classified, and $80.0 \%$ of unselected original grouped cases were correctly classified

\begin{tabular}{|cccccc|}
\hline & \multicolumn{5}{c|}{ Predicted membership } \\
& Type & 1 & 2 & 3 & Total \\
\hline Cases selected & & & & & \\
Original count & 1 & 1 & 9 & 0 & 10 \\
& 2 & 1 & 28 & 7 & 36 \\
Percentage & 3 & 0 & 1 & 67 & 68 \\
& 1 & 10.0 & 90.0 & 0 & 100.0 \\
Cases not selected & 2 & 2.8 & 77.8 & 19.4 & 100.0 \\
Original count & 1 & 3 & 12 & 0 & 15 \\
& 2 & 1 & 34 & 4 & 39 \\
Percentage & 3 & 0 & 5 & 51 & 56 \\
& 1 & 20.0 & 80.0 & 0 & 100.0 \\
& 2 & 2.6 & 87.2 & 10.3 & 100.0 \\
& 3 & 0 & 8.9 & 91.1 & 100.0 \\
\hline
\end{tabular}

Using this function we were able to statistically discriminate 2 different morphometric types in the 100 randomly selected Nodularia filaments; one corresponded to Type 3 filaments, the other encompassed routined Type 2 and 1 trichomes. This result may be significant in terms of the Nodularia assemblage sampled, implying that it can be considered typical of the entire natural community. Therefore this provides a

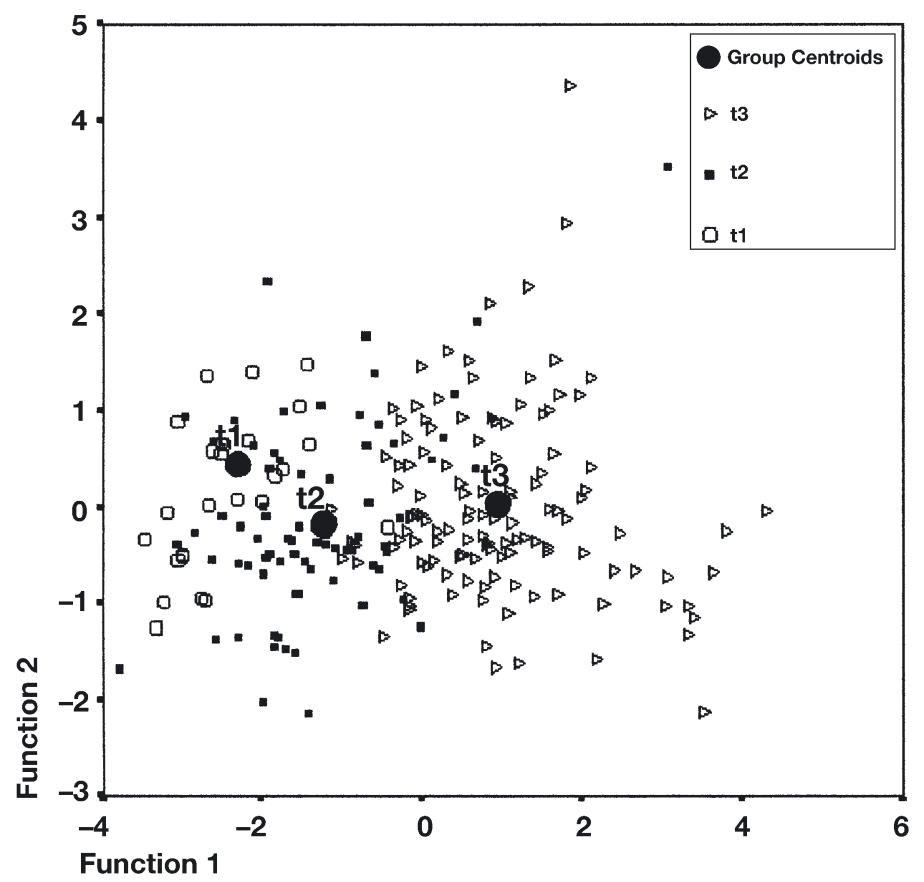

Fig. 5. Nodularia. Scatterplot of the 3 combined showing distribution of morphotypes and their group centroids
Table 4. Coefficients of the 2 standardized canonical discriminant functions used for the scatterplot in Fig. 5

\begin{tabular}{|lrr|}
\hline & \multicolumn{3}{c|}{ Function } & \multicolumn{1}{c|}{2} \\
\hline Area & 1 & -1.693 \\
Perimeter & -2.639 & 4.150 \\
Length & 1.706 & -2.974 \\
Width & 0.900 & 0.685 \\
\hline
\end{tabular}

Table 5. Correlations between discriminating variables and standardized canonical discriminant functions. Variables ordered by absolute size of correlation within function. *Largest absolute correlation between each variable and any discriminant function

\begin{tabular}{|lcc|}
\hline & \multicolumn{3}{c|}{ Function } \\
& 1 & 2 \\
\hline Length & $0.735^{*}$ & -0.022 \\
Perimeter & $0.621^{*}$ & 0.251 \\
Area & $0.357^{*}$ & 0.333 \\
Width & 0.311 & $0.644^{*}$ \\
\hline
\end{tabular}

description of the phenotypic diversity of this cyanobacterial genus in the late summer bloom community. Also, at least 2 different and more frequent morphotypes were shown to coexist in the field.

Measurement of the trichome/cell diameter, conducted on the 100 randomly selected Nodularia images, allowed us to further characterize the 3 types of filaments classified a priori during epifluorescence observation. The width of Type 3 filaments ranged from 11.1 to $18.8 \mu \mathrm{m}$, with a mean of $13.5 \mu \mathrm{m}(\mathrm{SD}=1.8$ and $0.2 \mu \mathrm{m}$ ), while Type 2 ranged from 7.7 to $12.7 \mu \mathrm{m}$ and the mean was $10 \mu \mathrm{m}$ (SD = 1.3 and $0.2 \mu \mathrm{m})$. It has to be pointed out that only 2 Type 2 filaments of 7 to 8 $\mu \mathrm{m}$ were observed out of 34 . Type 1 width range was lower than the others, between 7.2 and $8.8 \mu \mathrm{m}$, with a mean of $8.1 \mu \mathrm{m}(\mathrm{SD}=0.55$ and $0.2 \mu \mathrm{m})$. Nevertheless, during the previous image processing (Congestri et al. 2000), some filaments of ca. $6 \mu \mathrm{m}$ attributable to Type 1 were observed, although they were not randomly selected for the purpose of the present work.

\section{DISCUSSION}

Traditional cytomorphologic analysis and, to a lesser extent, ecological characters have long been used to classify natural cyanobacterial populations. In addition, the application of biometrical methods to sets of parameters provided reliable results, especially when linear dimensions (quantitative characters) were used to discriminate the different forms at genus and spe- 
cies level (Hoffmann 1988, Komárková 1988, Komárek \& Kováčik 1989, Bazzichelli \& Abdelahad 1994). The problem in finding limits in the distribution of the differentiating criteria within communities, so as to separate them into non-overlapping classes, makes it necessary to combine studies on natural and cultural material. Culture studies provided further characters to delineate species such as the physiological, biochemical and genetic variability of different strains. Therefore, the combination of traditional, chemotaxonomic and molecular approaches seemed promising for describing communities, populations and species diversity. However, in some cases this was a problem since molecular and genetic data, mostly based on the analysis of the 16S rRNA sequences, indicated that morphologic characters do not necessarily result in a phylogenetically reliable taxonomy (Wilmotte 1994). Furthermore, it was not always possible to combine different data into a meaningful taxonomic assessment, since the morphologic data did not always consistently reflect the similarities observed in the gene sequence. This was the case with the Baltic Nodularia (Hayes \& Barker 1997, Barker et al. 1999, Lehtimäki et al. 2000, Laamanen et al. 2001), the taxonomic status of which is currently being questioned. Three planktonic species have been described from Baltic isolates and field material, Nodularia litorea, N. spumigena and N. baltica (Komárek et al. 1993), on the basis of the traditional morphologic approach (morphology of the different types of cells, presence of gas vesicles, ultrastructural features), nodularin production and ecological characteristics. Further studies reported the presence of only the former 2 species in natural Nodularia assemblages (Walsby et al. 1995, Albertano et al. 1996). However, another form was less frequently observed which did not correspond to any of the previously recognized taxa (Walsby et al. 1995). By coupling genetic and morphologic data on 6 Baltic strains, the coexistence of distinct Nodularia species was confirmed, namely $N$. spumigena and $N$. sphaerocarpa, along with another isolate not currently described in any of the established taxa (Bolch et al. 1999). Conversely, other studies suggested an inconsistency between phenotypic and genotypic features for the purpose of congruency and accurate species delineation (Barker et al. 1999, Lehetimäki et al. 2000, Laamanen et al. 2001). A recent population genetic study revealed a high degree of genetic heterogeneity within 12 different genotypes, whose distribution demonstrated the occurrence of horizontal gene flow ultimately implying that a single 'species' does exist in the Baltic Sea (Barker et al. 2000a). This was later supported by Laamanen et al. (2001), who coupled genetic and phenotypic approaches with the aim of finding morphologic or molecular markers in order to discrim- inate between toxic and non-toxic strains of Nodularia in the field.

In the present study the application of discriminant analysis to the automatic datasets showed a clear-cut separation between 2 Nodularia groupings within the Baltic natural community. Despite the general consensus on the continuum represented by the morphologic variation of Baltic Nodularia, the discriminant function allowed statistical groupings of all Nodularia morphometric data into at least 2 distinct morphometric entities. Although the function was not able to clearly separate Type 1 from Type 2, the calculated ranges of trichome diameter for these morphotypes did not show any overlap, both when considering the mean values $\pm \mathrm{SE}$ or SD (mean $\pm \mathrm{SD}$ : Type $1=7.5-8.6$, Type $2=$ 8.7-11.3). Thus, it was possible to infer that $2 \mathrm{Nodu}-$ laria morphotypes co-occurred during cyanobacterial bloom formation in late summer in the Baltic Sea. These can be defined on the basis of the general morphology, trichome width and heterocyst morphometry. Whether these types represent different growth forms of a single Nodularia species related to the environmental conditions, nutrient status or life cycle stages cannot be ruled out. However, it is known that these 'forms' belonged to an actively growing assemblage that has been exposed to the same local environmental conditions and experienced N-starvation and $\mathrm{N}$ repleteness during the bloom formation observed (Gallon et al. 2002). The doubling of biomass between 6 and 11 July 1998 (Gallon et al. 2002), the lack of akinetes and the presence of mostly fluorescent heterocysts in our samples would indicate that the Nodularia filaments were presumably at the same stage of development. We considered them as units of morphologic/morphometric diversity, irrespective of their stillquestionable biological significance. In any case, one morphotype, Type 3, resembled the filament morphology reported for $N$. litorea (Kutz.) Thuret (Komárek et al. 1993). N. litorea is described as (9.5) 10-15 (18) um wide, with straight or curved trichomes, constricted at cross walls and characterized by very short, barrelshape cells, with discoid heterocysts of the same width as that of vegetative cells. Type 2, although not statistically separated from Type 1 , resembled $N$. spumigena Mertens characterized by straight, curved, spiral and coiled trichomes of (6) 6.8-12 (16) $\mu \mathrm{m}$ in width, constricted at cross walls and with discoid, cylindrical or barrel-shape cells and transversely oval heterocysts. Therefore, 2 of the morphotypes statistically distinguished in this study shared some morphologic features with species described on the basis of a classical taxonomic revision (Komárek et al. 1993), though no correspondence was found between the degree of filament coiling observed by us and that reported in the literature as a diacritical feature. 
The taxonomic assessment of Type 1 was another problem, although it resembled Nodularia baltica in heterocyst morphology, the latter being transversely oval to almost spherical and wider than vegetative cells. Further observations indicated that the tightly coiled filaments assigned to Type 1 could be statistically distinguished from Type 2 using our discriminant function .

Our aim was, therefore, to show an application of the image analysis-based method we developed in order to estimate filamentous cyanobacterial biomass in mixed-species natural assemblages.

Population genetic analysis of Nodularia partially carried out over the same area and period revealed that 3 out of the 12 allele-combinations distributed across the Baltic Sea were much more frequent than others (Barker et al. 2000a). These data suggest a correlation between the 3 genotypes and the 3 morphotypes observed by us. However, the frequency distribution reported for the 3 most abundant genotypes did not match that of our 3 morphotypes of Nodularia.

Using this system, the width distribution pattern of Aphanizomenon appeared to be rather close to normal and is confirmed by the most recent molecular data on the genotypic homogeneity of the Baltic Aphanizomenon population. This is considered to be clonal and not attributable to the species A. flos-aquae (Barker et al. 2000b), as indicated by Janson et al. (1994) on the basis of ultrastructural data.

Future application of this function could be used for a rapid morphometric assessment of natural Nodularia assemblage. It would be especially useful in fully automatic systems where highlighting of heterocysts in the filament would allow the automatic calculation of their linear dimensions.

Acknowledgements. We gratefully thank Dr. Maria Lo Ponte for improving the English in this manuscript and Dr. Palma Mattioli for her skillful assistance during image analysis processing. This work is a contribution to the European Union ELOISE Programme (ELOISE No. 377/15) within the framework of the BASIC project carried out under contract ENV4CT97-0571.

\section{LITERATURE CITED}

Albertano P, Di Somma S, Leonardi D, Canini A, Grilli Caiola M (1996) Cell structure of planktic cyanobacteria in the Baltic Sea. Arch Hydrobiol Suppl Algol Stud 83:29-54

Albertano P, Di Somma S, Capucci E (1997) Cyanobacterial picoplankton from the Central Baltic Sea: cell size classification by image-analyzed fluorescence microscopy. J Plankton Res 19 (10):1405-1416

Barker GLA, Hayes PK, O'Mahony SL, Vacharapiyasophon P, Walsby AE (1999) A molecular and phenotypic analysis of Nodularia (Cyanobacteria) from the Baltic Sea. J Phycol 35:931-937
Barker GLA, Handley BA, Vacharapiyasophon P, Stevens JR, Hayes PK (2000a) Allele-specific PCR shows that genetic exchange occurs among genetically diverse Nodularia (Cyanobacteria) filaments in the Baltic Sea. Microbiology 146:2865-2875

Barker GLA, Konopka A, Handley BA, Hayes PK (2000b) Genetic variation in Aphanizomenon (Cyanobacteria) colonies from the Baltic Sea and North America. J Phycol 36:947-950

Bazzichelli G, Abdelahad (1994) Caractérisation morphométrique et statistique de deux populations d'Aphanizomenon du groupe Aphanizomenon ovalisporum Forti des lacs de Nemi et Albano (Italie). Arch Hydrobiol/Suppl Algol Stud 73:1-21

Bolch CJS, Orr PT, Jones GJ, Blackburn SI (1999) Genetic, morphologic, and toxicological variation among globally distributed strains of Nodularia (Cyanobacteria). J Phycol 35:339-355

Carmichael WW, Eschedor JT, Patterson JML, Moore RE (1988) Toxicity and partial structure of a hepatotoxic peptide produced by the cyanobacterium Nodularia spumigena Mertens emend. L575 from New Zealand. Appl Environ Microbiol 54 (9):2257-2263

Carpenter EJ, Janson S, Boje R, Pollehne F, Chang J (1995) The dinoflagellate Dinophysis norvegica: biological and ecological observations in the Baltic Sea. Eur J Phycol 30: $1-9$

Congestri R, Federici R, Albertano P (2000) Evaluating biomass of Baltic filamentous cyanobacteria by image analysis. Aquat Microb Ecol 22:283-290

Finni T, Kononen K, Olsonen R, Wallström K (2001) The history of cyanobacterial blooms in the Baltic Sea. Ambio 30 $(4-5): 172-178$

Gallon JR, Evans AM, Jones DA, Albertano P and 14 others (2002) Maximum rates of $\mathrm{N}_{2}$ fixation and primary production are out of phase in a developing cyanobacterial bloom in the Baltic Sea. Limnol Oceanogr 47(5): $1514-1521$

Hayes PK, Barker GLA (1997) Genetic diversity within Baltic Sea populations of Nodularia (Cyanobacteria). J Phycol 33:919-923

Hewes CD, Mitchell BG, Moisan TA, Vernet M, Reid FMH (1998) The phycobilin signatures of chloroplasts from three dinoflagellate species: a microanalytical study of Dinophysis caudata, D. fortii, and D. acuminata (Dinophysiales, Dinophyceae). J Phycol 34:945-951

Hoffmann L (1988) Criteria for the classification of blue-green algae (cyanobacteria) at the genus and at the species level. Arch Hydrobiol/Suppl Algol Stud 50-53:131-139

Janson S, Carpenter EJ, Bergman B (1994) Fine structure and immunolocalisation of proteins in Aphanizomenon sp. from the Baltic Sea. Eur J Phycol 29:203-211

Kahru K, Horstman U, Rud O (1994) Satellite detection of increased cyanobacterial blooms in the Baltic Sea: natural fluctuation or ecosystem change? Ambio 23:469-472

Komárek J, Kováčik L (1989) Trichome structure of four Aphanizomenon taxa (Cyanophyceae) from Czechoslovakia, with notes on the taxonomy and delimitation of the genus. Plant Syst Evol 164:47-64

Komárek J, Hübel M, Hübel H, Šmarda J (1993) The Nodularia studies 2. Taxonomy. Arch Hydrobiol/Suppl Algol Stud 68:1-25

Komárková J (1988) Morphologic variation in natural populations of Anabaena lemmermannii in respect to the existence of Anabaena utermoehlii. Arch Hydrobiol/Suppl Algol Stud 50-53:93-108

Kononen K, Kuparinen J, Mäkelä K, Laanemets J, Pavelson J, 
Nõmmann S (1996) Initiation of cyanobacterial blooms in a frontal region at the entrance to the Gulf of Finland, Baltic Sea. Limnol Oceanogr 41(1):98-112

Laamanen MJ, Gugger MF, Lehtimäki J, Haukka K, Sivonen K (2001) Diversity of toxic and nontoxic Nodularia isolates (Cyanobacteria) and filaments from the Baltic Sea. Appl Environ Microbiol 67 (10):4638-4647

Lehtimäki J, Lyra C, Suomalainen S, Sundman P, Rouhiainen L, Paulin L, Salkinoja-Salonen M, Sivonen K (2000) Characterization of Nodularia strains, cyanobacteria from brackish waters, by genotypic and phenotypic methods. Int J Syst Evol Microbiol 50:1043-1053

Moisander PH, Pearl HW (2000) Growth, primary productivity, and nitrogen fixation potential of Nodularia spp. (Cyanophyceae) in water from a subtropical estuary in the United States. J Phycol 36:645-658

Niemi A (1979) Blue-green algal blooms and N:P ratio in the Baltic Sea. Acta Bot Fenn 110:57-61

Sellner KG (1997) Physiology, ecology, and toxic properties of marine cyanobacteria blooms. Limnol Oceanogr 42 (5): 1089-1104

Sivonen K, Kononen K, Carmichael WW, Dalhem AM, Rine-

Editorial responsibility: William Li,

Dartmouth, Nova Scotia, Canada hart KL, Kiviranta J, Niemelä SI (1989) Occurrence of the hepatotoxic cyanobacterium Nodularia spumigena in the Baltic Sea and structure of the toxin. Appl Environ Microbiol 55:1990-1995

Šmarda J, Komárek J, Čáslavská J, Hübel M (1988) The Nodularia studies 1. Introduction, fine structure. Arch Hydrobiol/Suppl Algol Stud 50-53:109-129

Stal LJ, Walsby AE (2000) Photosynthesis and nitrogen fixation in a cyanobacterial bloom in the Baltic Sea. Eur J Phycol 35:97-108

Stal LJ, Staal M, Villbrandt M (1999) Nutrient control of cyanobacterial blooms in the Baltic Sea. Aquat Microb Ecol 18:165-173

Walsby AE, Avery A (1996) Measurement of filamentous cyanobacteria by image analysis. J Microbiol Methods 26: $11-20$

Walsby AE, Hayes PK, Boje R (1995) The gas vesicles, buoyancy and vertical distribution of cyanobacteria in the Baltic Sea. Eur J Phycol 30:87-94

Wilmotte A (1994) Molecular evolution and taxonomy of the cyanobacteria. In: Bryant DA (ed) The molecular biology of cyanobacteria. Kluwer Academic, Dordrecht, p 1-25

Submitted: January 25, 2002; Accepted: April 23, 2003

Proofs received from author(s): July 4, 2003 